\title{
PENGARUH BUDAYA ORGANISASI TERHADAP NILAI PERUSAHAAN \\ DAN GCG SEBAGAI VARIABEL MODERATING
}

\author{
Verliani Dasmaran \\ Dosen Universitas Mathla'ul Anwar Banten \\ eeytea@gmail.com
}

\begin{abstract}
The purpose of this study is To know how the influence of organizational culture on Corporate Value and To Know how Good Corporate Governance can strengthen the influence of organizational culture on corporate value, the study population is 30 companies registered in CGPI (Coorporate Governance Persepsion Index) in 2015 and the sample research into 25 companies with research methods The type of research used is associative research that is associative technique of associative research using quantitative analysis technique (statistic). To know the amount of influence between variable of writer use data analysis with help SPSS 22 : The result of research proves that there is positive influence of Organization Culture to Company Value or hypothesis $\left(H_{1}\right)$ accepted, and $H_{2}$ rejected means Good Corporate Governance (GCG) Minimize the Effect of Organizational Culture Variables on Corporate Value.
\end{abstract}

Keyword : organizational culture, Good Corporate Governance, Corporate Value

\section{PENDAHULUAN}

Pasar merupakan tujuan semua pihak dalam menjalankan dunia bisnis, dunia usaha, dimana semua pelaku ekonomi bisa berinteraksi sehingga tujuan dari masing masing pihak tercapai. Dalam perusahaan nilai perusahaan ditentukan oleh nilai pasar dari saham yang beredar sehingga nilai tersebut membangun informasi bahwa perusahaan tersebut layak atau tidak untuk dijadikan sasaran investasi.

Gain capital adalah salah satu tujuan dari kepemilikan saham di sebuah perusahaan, maka gain capital ini yang berpengaruh besar tehadap nilai suatu perusahaan, semakin besar gain capital maka semakin tinggi nilai perusaaan, hal 
tersebut akan terjadi jika harga pasar lebih tinggi dari nilai nominal. Untuk meningkatkan harga pasar saham perusahaan tanggung jawab penuh managemen atau dewan direksi sehingga nilai perusahaan bisa dijadikan alat pengukuran kinerja manajemen

Isu yang lagi berkembang dimasyarakat tentang mundurnya perusahaan besar terlindas oleh perusahaan baru yang lebih inovasi dan dapat diterima masyarakat misalnya demonya para supir taxi argo akibat adanya taxi online, ojeg pangkalan berseturu dengan ojek online, berubahnya selera masyarakat dari belanja ditoko langsung menjadi belanja online. Berkurangnya omset berpengaruh terhadap nilai perusahaan sehingga inovasi di perusahaan berpengaruh terhadap nilai perusahaa.

Inovasi merupakan bagian dari budaya perusahaan hal ini sesuai dengan pendapat Mckenna et all yang diterjemahkan oleh budi santoso, 2002: 19 “ budaya yang kuat mendasari aspek kunci pelaksanaaan fungsi organisasi dalam hal efisiensi,inovasi,kualitas serta mendukung reaksi yang tepat untuk membiasakan mereka terhadap kejadian-kejadian, karena etos yang berlaku mangakomodasikan ketahanan"

Terdapat empat masalah budaya yang harus diperhatikan oleh perusahaan pertama menciptakan etika budaya,kedua menciptakan budaya inovasi, menciptakan budaya yang tanggap terhadap konsumen dan yang keempat adalah budaya dan spiritualistis organisasi

Sesuai dengan Signalling Theory atau teori sinyaldikembangkan oleh (Ross, 1977), menyatakan bahwa pihak eksekutif perusahaan memiliki informasi lebih baik mengenai perusahaannya akan terdorong untuk menyampaikan informasi tersebut kepada calon investor agar harga saham perusahaannya meningkat.Hal positif dalam signalling theory dimana perusahaan yang memberikan informasi yang bagus akan membedakan mereka dengan perusahaan yang tidak memiliki "berita bagus" dengan menginformasikan pada pasar tentang keadaan mereka, sinyal tentang 
bagusnya kinerja masa depan yang diberikan oleh perusahaan yang kinerja keuangan masa lalunya tidak bagus tidak akan dipercaya oleh pasar (Wolk dan Tearney dalam Dwiyanti, 2010).

Budaya organisasi merupakan salah satu berita atau informasi yang dapat disampaikan kepublik dan dijadikan sinyal bagi investor dalam membuat keputusan investasi, semakin banyak investor tertarik maka harga saham perusahaan naik, hal ini menandakan naiknya nilai perusahaan.

Selama ini meningkatkan nilai pasar dilakukan dengan pendekatan rasio rasio atau angka angka yang bersumber dari laporan keuangan sehingga investor bisa menganalisis kesehatan perusahan dan kinerja perusahaan serta peramalan-peramalan yang akan terjadi pada investasinya, tetapi kelemahannya kekuatan laporan tersebut dalam menggabarkan kondisi riil diperusahaan. Karena masih besar kemungkinan laporan disusun berdasarkan kepentingan manajemen. Disini penulis berusaha mengungkap nilai perusahaan tersebut dengan adanya informasi tentang budaya organisasi.

Budaya organisasi memberikan ketegasan dan mencerminkan spesifikasi suatu organisasi sehingga berbeda dengan organisasi lain. Budaya organisasi melingkupi seluruh pola perilaku anggota organisasi dan menjadi pegangan bagi setiap individu dalam berinteraksi, baik di dalam ruang lingkup internal maupun ketika berinteraksi dengan lingkungan eksternal. Budaya perusahaan dapat memberikan informasi kepada pasar sehingga kepercayaan investor meningkat dan dapat meningkatkan harga pasar.

Isu kebijakan pemerintah di negara tujuan menjadi salah satu faktor yang dijadikan pertimbangan sebelum menempatkan portofolio di negara tersebut,seperti halnya kebijakan pemerintah mengenai GCG dari penjelasan tersebut maka penulis tertarik untuk mengetahui bagaimana "Pengaruh Budaya Organisasi Berpengaruh Terhadap Nilai Perusahaan Dengan GCG Sebagai Variable Moderator”. 
Berdasarkan uraian diatas maka masalah dalam penelitian dirumuskan sebagai sebagai berikut:

\section{Budaya Organisasi}

Riset ini bermaksud mengkomfirmasi apakah Budaya Organisasi dalam Perusahaan memiliki hubungan yang fositif dan signifikan terhadap Nilai perusahaan. Penelitian ini menkomfirmasi nilai perusahaan diukur dengan Tobin q rasio.

\section{Good Coorporate Governance}

Rumusan masalah dalam penelitian ini dirancang untuk mengetahui apakah Good Coorporate Governance Memoderasi hubungan antar Budaya Organisasi dengan Nilai Perusahaan dengan proxy tobin q rasio

Berdasarkan perumusan masalah di atas, maka tujuan dari penelitian ini adalah untuk menguji pengaruh budaya Organisasi terhadap Nilai Perusahaan dikaitkan dengan harga saham melaui nilai tobins q dan menjadi pertimbangan dalam penerapan Good Coorporate governance sesuai dengan peraturan dan kondisi perusahaan diindonesia.

Penelitian ini diharapkan memberikan kontribusi teorimemberikan kontribusi teori tentang budaya organisasi, ukuran Perusahaan dan Good Coorporate Govennance dapat mempengaruhi tinggi rendahnya harga pasar perusahan.Serta Kontribusi Praktekbagaimana cara meningkatkan nilai pasar dari suatu perusahaan sehingga investor semakin tertarik, serta Kontribusi Kebijakanakan memberikan gambaran mengenai hal-hal yang berdampak pada peningktan nilai perusahaan sehingga berpengaruh terhadap kebijakan yang dikeluarkan manajemen ataupun pemerintah dalam rangka meningkatkan perekonomian bangsa 


\section{TINJAUAN PUSTAKADAN HIPOTESIS}

\section{LANDASAN TEORI}

Stewardship theory dibangun di atas asumsi filosofis mengenai sifat manusia yakni bahwa manusia pada hakekatnya dapat dipercaya, mampu bertindak dengan penuh tanggung jawab memiliki, integritas, dan kejujuran terhadap pihak lain. Inilah yang tersirat dalam tuntutan yang dikehendaki para pemegang saham. Dengan kata lain, stewardship theory memandang manajemen sebagai dapat dipercaya untuk bertindak dengan sebaik-baiknya bagi kepentingan publik pada umumnya maupun shareholders pada khususnya.

Selain stewardship theory yang memberi kepercayaan kepada manajemen penelitian ini juga dilandasi dengan signaling theory yaitu teori yang mendukung bahwa apa yang sudah dikerjakan oleh manajemen merupakan informasi atau sinyal yang harus diberikan dan membantu semua pemangku kepentingan dalam menentukan kebijakan. T. C. Melewar (2008:1) menyatakan teori sinyal menunjukan bahwa perusahaan akan memberikan sinyal melalui tindakan dan komunikasi dan komunikasi, perusahaan ini mengadopsi sinyal sinyal ini untuk mengungkapkan atribut yang tersembunyi untuk para pemangku kepentingan.

\section{Pengertian budaya Organisasi}

Pengertian budaya organisasi menurut Robbins (2014) adalah suatu sistem makna bersama yang dianut oleh anggota-anggota yang membedakan organisasi tersebut dengan yang lain.sedangkan menurut Walter R.Freytag (2013) adalah asumsi-asumsi dan nilai-nilai yang disadari atau tidak disadari yang mampu mengikat kepaduan suatu organisasi. Asumsi dan nilai tersebut menentukan pole perilaku para anggota didalam organisasi.

\section{Fungsi Budaya Organisasi}

Budaya organisasi memiliki beberapa fungsi yang dapat dilihat dibawah ini:

- Penambah komitmen organisasi dan sebagai perasaan identitas 
- Untuk alat pengorganisasisan anggota

- Untuk sebagai penguat nilai-nilai dalam organisasi

- Sebagai mekanisme kontrol perilaku

- Untuk meningkatkan dan mendorong kinerja ekonomi baik dalam jangka panjang dan jangka pendek

- Sebagai penentu suatu arah organisasi dalam hal mana yang boleh dan tidak boleh

\section{Pengertian Nilai perusahaan}

Nilai perusahaan (Value Of The Firm) merupakan kondisi tertentu yang telah dicapai oleh suatu perusahaan sebagai gambaran dari kepercayaan masyarakat terhadapperusahaan setelah melalui suatu proses kegiatan selama beberapa tahun, yaitu sejak perusahaan tersebut didirikan sampai dengan saat ini. Nilai perusahaan pada dasarnya diukur dari beberapa aspek salah satunya adalah harga pasar saham perusahaan, karena harga pasar saham perusahaan mencerminkan penilaian investor atas keseluruhan ekuitas yang dimiliki (Wahyudi dan Pawestri, 2006 dalam Permanasari, 2010)

Tobin's q merupakan rasio dari nilai pasar asset perusahaan yang diukur oleh nilaipasar dari jumlah saham yang beredar dan hutang (enterprise value) terhadap replacement cost dari aktiva perusahaan (Fiakas, 2005).

\section{Good Corporate Governance}

Corporate Governance sebagai proses dan struktur yang diterapkan dalam menjalankan perusahaan, dengan tujuan utama untuk meningkatkan nilai pemegang saham dalam jangka panjang tetap memperhatikan kepentingan stake holder (IICG dalam G Suprayitno et all 2004:18).

Good Corporate Governance akan memberikan empat manfaat besar (Wilson Arafat, 2008:10), yaitu: 
a. Meningkatkan kinerja perusahaan melalui terciptanya proses pengambilan keputusan yang lebih baik, meningkatkan efisiensi operasional perusahaan serta lebih meningkatkan pelayanan kepada stakeholders.

b. Meningkatkan corporate value.

c. Meningkatkan kepercayaan investor.

d. Pemegang saham akan merasa puas dengan kinerja perusahaan karena sekaligus akan meningkatkan shareholder's value dan dividen.

Model penelitian dapat digambarkan pada gambar dibawah ini:

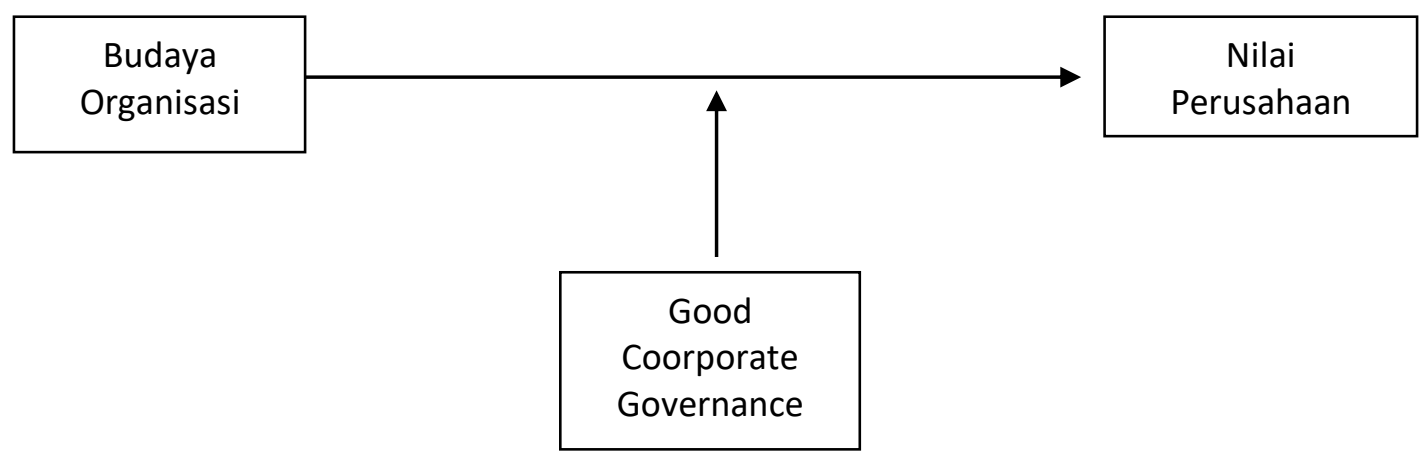

Gambar 2.1

\section{Rerangka Teoritis}

\section{PENGEMBANGAN HIPOTESIS}

\section{Pengaruh Budaya Organisasi Terhadap Nilai Perusahaan}

Budaya Organisasi merupakan hal penting untuk meningkatkan kinerja karyawan dan secara logika kinerja karyawan meningkat maka akan berdampak pada kontinuitas dari perusahaan, semakin baiknya continuitas perusahaan maka berdampak pada peningkatan nilai perusahaan, maka menjadi hal penting ditekankan adanya budaya organisasi dalam setiap perusahaan. Menurut Siagian (2002:201) budaya organisasi mengacu ke suatu sistem makna bersama yang dianut anggota anggota yang membedakan perusahaan itu terhadap perusahaan lain. Budaya 
perusahaan atau budaya manajemen atau juga dikenal dengan istilah budaya kerja merupakan nila inilai dominan yang disebar luaskan di dalam organisasi dan diacu sebagai filosofi kerja karyawan,Moeljono Djokosantoso (2003: 17 dan 18). Dalam penelitian Ida Ayu Brahmasari dan Agus Suprayetno(2008) menyatakan bahwa budaya organisasi berpengaruh signifikan terhadap kinerja perusajaan, sehingga penulis mengembangkan hipotesisnya menjadi

\section{$H_{1}:$ Budaya Organisasi berpengaruh positif terhadap Nilai Perusahaan}

\section{Good Coorporate Governance (GCG) sebagai Pemoderasi Pengaruh Budaya Organisasi terhadap Nilai Perusahaan}

Mekanisme pelaksanaan Good Corporate Governance (GCG) terdiri dari mekanisme internal dan eksternal, mekanisme internal yaitu pelaksanaan yang dilaksanakan didalam manajemen perusahaan sehinggga perusahaan dapat berjalan dengan ketentuan dan kebijakan kebijakan yang dapat memberi dampak positif terhadap pergerakan pasar saham dari perusahaan tersebut, sedangkan mekanisme eksternal pelaksanaan yang terbentu oleh pasar sehingga jelas bagaimana GCG dapat mempengaruhi nilai perusahaan, seperti pada penelitian Kapler dan Love (2002) menemukan adanya hubungan positif antara corporate governance dengan kinerja perusahaan yang diukur dengan return on assets (ROA) dan Tobin's Q., sedangkan menurut (Susanti, 2011) Corporate governance (CG) secara umum adalah seperangkat mekanisme yang saling menyeimbangkan antara tindakan maupun pilihan manajer dengan kepentingan shareholders.

Good Coorporate Governance memiliki kekuatan terhadap budaya integritas yang tinggi sehingga terdapat hubungan antara budaya organiasasi dengan Good Coorporate Govenance.Maka dari itu seberapa besar GCG berpengaruh terhadap nilai perusahaan maka penulis mengembangkan hipotesis kedua menjadi:

\section{$\mathrm{H}_{2}$ Good Coorporate governance memperkuat hubungan Budaya Organisasi Dengan Nilai Perusahaan}




\section{METODELOGI PENELITIAN}

\section{Variable Penelitian dan Pengukurannya}

Variable dependen dalam penelitian ini adalah nilai perusahaan dengan menggunakan proksi tobin q rasio yaitu nilai jual perusahaan atau nilai tumbuh bagi pemegang saham ( andri dan Hanung 2007 dalam Reny Diah 2013 ) diperoleh dengan rumus $\frac{\text { EquitymarketRatio+LiabilitiesBookvalue }}{\text { equitybookratio+liabilitiesBookRatio }}$

Sedangkan untuk Total Market Value $=$ Total OutstandingxCurrent share's Price Skor Interpretasi Tobin's q

Jika nilai tobin q < 1 Menggambarkan bahwa saham dalam kondisi undervalued.

Jika Tobin's q = 1 Menggambarkan bahwa saham dalam kondisi average.

Jika Tobin's q > 1 Menggambarkan bahwa saham dalam kondisi overvalued.

Variabel independen merupakan variabel yang mempengaruhi variable dependen, dalam penelitian ini yang merupakan variabel independen adalah budaya organisasi, hasil penelitian David Drennan selama sepuluh tahun telah ditemukan dua belas faktor pembentuk budaya organisasi /perusahaan/budaya kerja/budaya akdemis yaitu :

1) Pengaruh dari pimpinan

2) Sejarah dan tradisi organisasi

3) Teknologi, produksi dan jasa

4) Industri dan kompetisinya/ persaingan antar perguruan tinggi.

5) Pelanggan/stakehoulder akademis

6) Harapan perusahaan/organisasi

7) Sistem informasi dan kontrol

8) Peraturan dan lingkungan perusahaan

9) Prosedur dan kebijakan

10) Sistem imbalan dan pengukuran

11) Organisasi dan sumber daya

12) Tujuan, nilai dan motto. 
Dari faktor pembentuk budayaan organisasi tersebut maka di terapkan penilaian dengan berdasarkan laporan tahunan dan sustainability report jika melaporkan pembentuk kebudayaan berdasarkan devid drenan maka diberi skor 1 dan jika tidak melaporkan diberi skor 0 per item sehingga jika melaporkan semua nya memiliki skor 12 sebagai skor tertingi

Variabel moderating, yaitu tipe variabel-variabel yang memperkuat atau memperlemah hubungan langsung antara variabel independen dengan variabel dependen. Dalam penelitian ini yang menjadi variable moderasi yaitu Good Corporate Governance ( GCG) dengan proxy index GCG yang dinilai oleh CGPI (Coorporate Governance Perception Index) pada tahun 2015 dan terbit dibulan desember 2016.

\section{Objek Penelitian}

Objek penelitian ini adalah perusahaan peserta CGPI yang terdaftar di Bursa Efek Indonesia periode 2015, dimana untuk pengambilan data-data seperti laporan keuangan melalui situs www.idx.co.id. Populasi penelitian adalah 30 perusahaan yang terdaftar sebagai peserta CGPI sedangkan sample penelitian adalah 30 perusahaan Teknik pengambilan sampel yang digunakan dalam penelitian ini adalah adalah sensus atau sampel jenuh yaitu semua popilasi dijadikan sampel.

\section{Pengumpulan Data}

Pengumpulan data yang dilakukan penulis dengan metode observasi dan teknik pengumpulan data arsip dimana data yang diolah adalah data sekunder yaitu data kuantitatif yang disediakan oleh organisasi ( unit bisnis) sehingga peneliti tinggal menggunakan dan mengolah data 


\section{HASIL DAN PEMBAHASAN}

Jenis penelitian yang digunakan adalah penelitian Asosiasif yaitu Teknik analisis penelitian asosiatif menggunakan teknik analisis kuantitatif (statistik). Untuk mengetahui besarnya pengaruh antar variable penulis menggunakan analisis data dengan bantuan SPSS v 2

\section{Analisis Data}

Statistik deskriptif untuk variable yang diukur dalam penelitian ini yaitu Budaya Organisasi, Budaya Organisasi_GCG, Nilai Perusahaan dapat diamati pada table 1.

Table 1

Statistik Deskriptif

\begin{tabular}{|r|r|l|l|r|r|r|r|r|}
\hline & \multicolumn{1}{|c|}{$\mathrm{N}$} & \multicolumn{1}{l|}{ Range } & Minimum & Maximum & \multicolumn{2}{|c|}{ Mean } & Deviation & Variance \\
\cline { 2 - 8 } & Statistic & tatistic & Statistic & Statistic & Statistic & Std. Error & Statistic & Statistic \\
\hline Budaya_Organisasi & 30 & 5.00 & 6.00 & 12.00 & 8.9667 & .24674 & 1.35146 & 1.826 \\
Nilai_Perusahaan & 30 & 3.00 & 2.22 & 5.22 & 3.4070 & .14020 & .76793 & .590 \\
BO_GCG & 30 & 524.65 & 501.54 & 1026.19 & 740.9560 & 26.33049 & 144.21805 & 0798.846 \\
GCG & 30 & 21.35 & 71.94 & 93.29 & 82.2370 & 1.09120 & 5.97676 & 35.722 \\
Valid N (listwise) & 30 & & & & & & & \\
\hline
\end{tabular}

Variabel Budaya Organisasi memiliki nilai minimum 6 dan maksimum 12 dan memilik rata rata 8,9667, standar deviasi 1,35146, Nilai perusahaan memiliki nilai minimum 2.22 dan nilai maksimum 5.22, nilai rata rata 3,4070, standar deviasi 0,76793, sedangkan untuk BO_GCGC atau GCG sebagai variable moderasi memiliki nilai minimum 524.65 nilai maksimum 1026.19, nilai rata rata 740,9560 standar deviasi 144.21805 


\section{Uji Asumsi Klasik}

\section{Uji Normaitas}

Untuk menguji normalitas data variable penelitian menggunakan OneSample Kolmogorov-Smirnov Test tergambar dalam table 2 dibawah ini

Table 2

One-Sample Kolmogorov-Smirnov Test

\begin{tabular}{|rr|r|}
\hline & & $\begin{array}{r}\text { Unstandardized } \\
\text { Residual }\end{array}$ \\
& & 30 \\
Normal Parametersa,b & Mean & $0 \mathrm{E}-7$ \\
& Std. Deviation & .36257659 \\
Most Extreme Differences & Absolute & .135 \\
& Positive & .135 \\
& Negative & -.057 \\
mp. Sig. (2-tailed) & .739 \\
& & .646 \\
\hline
\end{tabular}

a. Test distribution is Normal.

b. Calculated from data.

Dari table 2 dapat dilihat nilai sig(2-tailed) $0,646>0,05$ sehingga dapat disimpulkan bahwa data penelitian berdistribusi normal

\section{Uji Multikoliniearitas}

Uji multikolinieritas bertujuan untuk menguji variable bebas dalam penelitian dengan model regresi harus bersifat independent ( tidak ada korelasi yang baik antar variable bebas) satu dengan yang lain, hasil uji multikolinearias dapat terlihat pada table 3 dibawah ini

Table 3

Uji Multikolinieritas

\begin{tabular}{|c|c|c|c|c|c|c|c|}
\hline \multicolumn{8}{|c|}{ Coefficients $^{a}$} \\
\hline \multirow[t]{3}{*}{ Model } & \multirow{2}{*}{\multicolumn{2}{|c|}{$\begin{array}{r}\text { Unstandardized } \\
\text { Coefficients }\end{array}$}} & \multirow{3}{*}{\begin{tabular}{|l} 
Standardized \\
Coefficients
\end{tabular}} & \multirow[t]{3}{*}{$\mathrm{T}$} & \multirow[t]{3}{*}{ pig. } & \multirow{2}{*}{\multicolumn{2}{|c|}{ Collinearity Statistics }} \\
\hline & & & & & & & \\
\hline & $\mathrm{B}$ & Std. Error & & & & Tolerance & VIF \\
\hline (Constant) & 3.854 & 5.604 & & .688 & .497 & & \\
\hline Budaya_Organisasi & .629 & .153 & 1.107 & 4.098 & .000 & .110 & 9.078 \\
\hline
\end{tabular}




\begin{tabular}{l|l|l|l|l|l|l|l|} 
In_B0_GCG & -.924 & 1.045 & -.239 & -.884 & .384 & .110 & 9.078 \\
\hline
\end{tabular}

a. Dependent Variable: Nilai_Perusahaan

Dari table 3 dapat dilihat nilai VIF $9.078>10$ maka data penelitian terbebas dari multikolinieritas

\section{Uji Heterokedasitas}

Uji heterokedasitas untuk menilai apakah ada ketidak samaan varian dari residual untuk semua pengamatan pada model regresi linier, uji heterokedasitas tergambar pada table 4

Table 4

Uji Heterokedasitas

\begin{tabular}{|c|c|c|c|c|c|}
\hline \multirow[t]{2}{*}{ Model } & \multicolumn{2}{|c|}{ standardized Coefficients } & \multirow{2}{*}{\begin{tabular}{|c} 
tandardized \\
Coefficients
\end{tabular}} & \multirow[t]{2}{*}{$\mathrm{T}$} & \multirow[t]{2}{*}{ Sig. } \\
\hline & $\mathrm{B}$ & Std. Error & & & \\
\hline (Constant) & .158 & .314 & & .503 & .619 \\
\hline 3udaya_Organisasi & -.037 & .094 & -.227 & -.392 & .698 \\
\hline BO_GCG & .001 & .001 & .404 & .697 & .492 \\
\hline
\end{tabular}

a. Dependent Variable: RES_2

Dari table diatas diperoleh nilai signifikanssi ( sig) bernilai > dari 0,05 yaitu 0,698.>0,05 dan dari BO*GCG yaitu 0,492 ini menunjukan baha semu variable tidak mengandung hetrokedasitas

\section{Hasil Regresi}

Uji regresi diperoleh pada table 5

\section{Table 5}

\begin{tabular}{|l|c|c|c|c|c|}
\hline Model & \multicolumn{2}{|c|}{ Coefficients $^{\mathbf{a}}$} \\
& Unstandardized Coefficients & $\begin{array}{c}\text { Standardized } \\
\text { Coefficients }\end{array}$ & Sig. \\
\cline { 1 - 5 } & $\mathrm{B}$ & Std. Error & Beta & \\
\hline
\end{tabular}




\begin{tabular}{|l|r|r|r|r|r|}
\hline \multirow{2}{*}{ (Constant) } & -1.125 & .466 & & -2.416 & .023 \\
budaya_organisasi & .066 & .017 & 1.039 & 3.972 & .000 \\
bo_gcg & $-8.224 \mathrm{E}-005$ & .000 & -.141 & -.537 & .595 \\
\hline
\end{tabular}

a. Dependent Variable: Nilai_usahaan

Dari table 5 dapat diperoleh nilai persmaan regresi $\mathrm{Y}=-1,125+0,066 \mathrm{x}_{1}$ $8,224 \mathrm{x}_{2}$ sehingga dapat diartikan

- Nilai konstanta -1,125 yaitu jika budaya organisasi tidak ada maka nilai perusahaan ( tobin q ) adalah -1.125 atau under value

- Nilai koefisien 0,06 X1 yaitu budaya organisasi memiliki pengaruh positif terhadap nilai perusahaan jika budaya organisasi meningkat sebesar $1 \%$ maka akan meningkatkan nilai perusahaan sebesar 0,06 atau $6 \%$

- $\quad$ Tingkat signifikansi 0,025 ( uji satu pihak ) $>$ F prob $(0,00)$

\section{Korelasi Dan Determinasi}

Untuk melihat berapa besar keeratan hubungan dan kontribusi budaya organisasi dan nilai perusahaan serta GCG sebagai variable moderasi dapat dilihat pada table 6 dibawah ini:

Table 6

Model Summary

\begin{tabular}{|l|r|r|r|r|}
\hline Model & \multicolumn{1}{|c|}{$\mathrm{R}$} & R Square & \multicolumn{1}{c|}{$\begin{array}{c}\text { Adjusted R } \\
\text { Square }\end{array}$} & $\begin{array}{c}\text { Std. Error of the } \\
\text { Estimate }\end{array}$ \\
\hline 1 & $.882^{\mathrm{a}}$ & .777 & .761 & .37577 \\
\hline
\end{tabular}

a. Predictors: (Constant), BO_GCG, Budaya_Organisasi

Dari table 6 dilihat nilai $\mathrm{R}$ yaitu 0,882 artinya budaya organisasi memili hubungan yang kuat (sugiono, table interprestasi r), dan budaya organisasi dan GCG memberikan kontribusi 0,761 atau $76,1 \%$ terhadap nilai perusahaan.

\section{Pengujian Hipotesis}

$H_{1}$ : Budaya Organisasi berpengaruh positif terhadap Nilai Perusahaan 
Berdasarkan regresi table 5 diperoleh persamaan $Y=-1,125+0,066 \mathrm{x}_{1}$ $8,224 \mathrm{x}_{2}$ sehingga dapat disimpulkan bahwa budaya organisasi memberikan pengaruh positif terhadap nilai perusahaan jika budaya organisasi ditingkatkan akan meningkatkan pula nilai perusahaan hal ini membuktikan bahwa budaya organisasi yang ditunjukan dalam laporan tahunan, sustainability reporting dapat memberikan sinyal positif bagi nilai perusahaan dengan proxy tobins q artinya semua budaya organisasi perusahaan yang diterapkan dan dlaporkan akan berdampak pada pergerakan harga saham, sehingga hopotesis awal $\mathrm{H}_{1}$ bahwa budaya organisasi berpengaruh positif terhadap nilai perusahaan diterima.

\section{$\mathrm{H}_{2}$ :Good Coorporate governance memperkuat hubungan Budaya Organisasi Dengan Nilai Perusahaan}

Untuk menguji hipotesis variable Good Coorporate Governance sebagai variable moderating dapat dilihat pada table 5jika nilai koefisien dari Bo_GCG lebih besar dari koefisien Budaya organisais maka hipotesis GCG sebagai variable moderasi dapat memperkuat Budaya Oranisasi terhadap nilai perusahaan tetapi hasil penelitian pada tabel 5 membuktikan bahwa GCG bukan sebagai variable moderasi karena memiliki koefisien BO_GCG< Budaya organisasi dan nilai signifikansi $0.569>$ 0,025 ini membuktikan bahwa hipotesis ditolak bahwa GCG bukan sebagai variable moderasi tidak terbukti dapat memperkuat atau memperlemah hubungan budaya organisasi dengan Nilai perusahaan

\section{SIMPULAN DAN KETERBATASAN}

Hasil penelitian ini menegaskan bahwa budaya organisasi berpengaruh positif terhadap nilai perusahaan atau dengan kesimpulan hipotisis diterima,dan Good Coorporate Governance tidak terbukti sebagai variable moderasi atau hipotesis $\left(\mathrm{H}_{2}\right)$ ditolak, ini membuktikan bahwa laporan tahunan baik itu laporan keuangan, laporan keberlanjutan ( sustainability report) dan index GCGtidak mampu memberikan sinyal positif terhadap nilai perusahaan karena nilai perusahaan menggunakan proxy tobin q berhubungan dengan perkembangan harga pasar saham, 
semakin bagus infromasi yang diberikan dari laporan tersebut dapat memperkuat harga saham.

\section{Keterbatasan}

Keterbatasan dalam penelitian ini yaitu pada objek penelitian tidak dibedakan sektor usaha hanya terfokus pada perusahaan yang mengajukan diri untuk untuk di nilai skor GCG pada CGPI oleh IICG sehingga semua sektor dan sifatnya voluntary ( sukarela) sehingga memiliki kemungkinan besar memiliki ketimpangan data antar objek atau sampel penelitian.

\section{DAFTAR PUSTAKA}

Cooper\&Schindler (2017) Metode Penelitian Bisnis, Salemba Empat ,Jakarta

FCGI. 2003. Seri Tata Kelola Peusahaan ( Corporate Governance) Jilid II. Jakarta : FCGI.

Fiakas, D, 2005. Tobin's q: Valuing Small Capitalization Companies, Crystal. Equity Research,

Ghozali(2013) Aplikasi Analisis Multivariete, Badan Penerbit,Universitas Diponegoro,semarang

Gujurati, Porter (2010) Dasar-Dasar Ekonometrika, Salemba Empat, Jakarta

Kotter\& Heskett, (1992) Corporate Culture and Performance,

Riduwan. 2012. Dasar-dasar Statistika. Bandung: Alfabeta

Riyanto, Bambang. 2008. Dasar-DasarPembelanjaan Perusahaan EdisiKeempat. Yogyakarta: BPFE Yogyakarta

Ida Ayu Brahmasari dan Agus Suprayetno (2008) Pengaruh Motivasi Kerja, Kepemimpinan dan Budaya Organisasi Terhadap Kepuasan Kerja Karyawan serta Dampaknya pada Kinerja Perusahaan (Studi kasus pada PT. Pei Hai International Wiratama Indonesia) Jurnal Manajemen Dan Kewirausahaan, VOL.10, NO. 2, SEPTEMBER 2008: 124-135 
Robbins Stephen (2008), Organizational Behaviour, tent edition, PT Gramedia Pustaka

Sekaran, Roger Bougie ( 2017) Metode Penelitian Untuk Bisnis, Salemba Empat Jakarta.

Sugiyono. 2014. Metode Penelitian Kuantitatif, Kualitatif dan R\&D. Bandung: Alfabeta.

Sulistiyanto, H. Sri. 2008. Manajemen Laba Teori dan Model Empiris. Jakarta : Grasindo

Wolk dan Tearney (2003) Accounting teory 